\title{
DEVELOPMENT AND VALIDATION OF AN LC- MS/MS METHOD FOR DETERMINATION OF RESIDUAL 2,4-DICHLOROPHENOXYACETIC ACID HERBICIDE IN PALM OIL
}

\author{
NAJWA SULAIMAN ${ }^{1 *}$; YEOH CHEE BENG ${ }^{1}$; NIK SASHA KHATRINA KHAIRUDDIN ${ }^{1}$ \\ and FARAH KHUWAILAH AHMAD BUSTAMAM ${ }^{1}$
}

\begin{abstract}
2,4-dichlorophenoxyacetic acid (2,4-D) is listed as one of the most widely used herbicides in Malaysian oil palm plantation and hence it is important to use validated methods for analysis of possible pesticide contamination in palm oil supply chain. This article reports on the development of an analytical method for the determination of residual 2,4-D in crude palm oil (CPO) using a liquid chromatography tandem mass spectrometry quadrupole time of flight (LC-QToF-MS). The method of analysis was based on a liquid-liquid extraction using methanol, heating of samples and low temperature precipitation technique. Evaluation of validation parameters such as linearity, matrix effect, selectivity, limit of detection (LOD), limit of quantification (LOQ), precision and recovery for CPO were performed. The results showed good linearity with average coefficient of determination $\left(r^{2}\right)$ of more than 0.99. The LOD and LOQ for analysis of residual 2,4-D was estimated at 5.0 and $10.0 \mathrm{ng}^{-1-1}$, respectively. Acceptable recoveries between $85 \%$ and $117 \%$, repeatability with good relative standard deviation (RSD) of 5\% to $10 \%$ and intermediate precision with RSD of less than $11 \%$ were obtained. Random monitoring of CPO showed that 2,4-D was not detected in any of the $C P O$ samples.
\end{abstract}

Keywords: 2,4-dichlorophenoxyacetic acid, crude palm oil, LC-MS/MS, method validation.

Received: 28 July 2021; Accepted: 19 August 2021; Published online: 26 October 2021.

\section{INTRODUCTION}

In 2020, Malaysia produced and exported 19.14 and 4.45 million tonnes of crude palm oil (CPO), respectively (MPOB, 2020). CPO is mainly used for the production of various palm-based derivatives for both food and non-food applications such as margarine, salad dressings, tocotrienol-richfractions enriched chewable tablet, cream cheese, surfactants, adjuvants for cosmetics, agricultural

1 Malaysian Palm Oil Board, 6 Persiaran Institusi, Bandar Baru Bangi, 43000 Kajang, Selangor, Malaysia.

* Corresponding author e-mail: najwa.sulaiman@mpob.gov.my chemicals and many other household items (Mat Dian et al., 2019; Pande et al., 2012; Yeong et al., 2012).

In Malaysia, the common weeds in oil palm plantations are Imperata cylindrica (lalang), Mikania sp., Clidemia sp. and Chromolaena odorata (Siam weed) (Jannick and Robert, 2008). These weeds compete with the oil palm trees for water, nutrients, and sunlight. This competition may affect growth and production of palm oil. Accumulation of weeds on the soil will hinder access of field operation (Jannick and Robert, 2008).

2,4-dichlorophenoxyacetic acid or 2,4-D $\left(\mathrm{C}_{8} \mathrm{H}_{6} \mathrm{Cl}_{2} \mathrm{O}_{3}\right)$ is among the herbicides registered for use in Malaysian oil palm plantations, apart from glyphosate, diuron, gluphosinate ammonium and metsulphuron methyl (Malaysian Federal 
Government Gazette, 2020). It was reported that $2,4-\mathrm{D}$ is widely used in oil palm plantation to control broad leaf weeds such as Asystasia gangetica, Borreria latifolia, Cleome rutidosperma, Clidemiahirta, Diodiaocimifolia and Mikania micrantha (Ngah et al., 2011). 2,4-D is preferable by the planters due to its good selectivity and cost-effectiveness (Mehdi et al., 2011). 2,4-D may be used alone or as a mixture consisting of a combination of dicamba, metsulphuron methyl and triclopyr to control a wide range of woody and herbaceous broad leaf weeds (Murphy, 2011). This herbicide is under the phenoxy family. 2,4-D can either be in colourless crystals or colourless liquid and its melting point is $140.5^{\circ} \mathrm{C}$. $2,4-\mathrm{D}$ has a high solubility in water $(620$ $\mathrm{mg}$ litre ${ }^{-1}$ ) and its molecular weight is $221.0 \mathrm{~g} \mathrm{~mol}^{-1}$ (MacBean, 2012). This herbicide is under class II toxicity World Health Organisation (WHO) and is moderately toxic to humans, as it can cause serious eye and skin irritation (MacBean, 2012). Figure 1 shows the chemical structure of 2,4-D.

The quality and safety of food products are always of interest to consumers and the respective authorities. This includes monitoring the presence of contaminants such as pesticide residues using validated analytical methods. From the literatures, methods for analysis of 2,4-D were described in various matrices such as eggs, milk, oranges, soil, water and olives (Chamkasem and Morris, 2016; Chen et al., 2015; Garcia-Reyes et al., 2007; Ismail et al., 2011; Mehdi et al., 2011), however none in palm oil matrix. With regard to fatty matrix, Hua et al. (2018) reported the use of molecular imprinted polymer surface enhanced Raman spectroscopy for detection and quantification of 2,4-D in milk, while Chen et al. (2018) quantified 2,4-D in rat serum using high-performance liquid chromatography (HPLC) with ultraviolet (UV) detector and obtained average recovery of $101 \%$ with relative standard deviation (RSD) of below $8 \%$.

The use of QuEChERS (quick, easy, cheap, effective, rugged, and safe) and solid phase extraction (SPE) technique and subsequent quantification by liquid chromatography with tandem mass spectrometry (LC-MS/MS) in negative ionisation mode was reported by Guo et al.

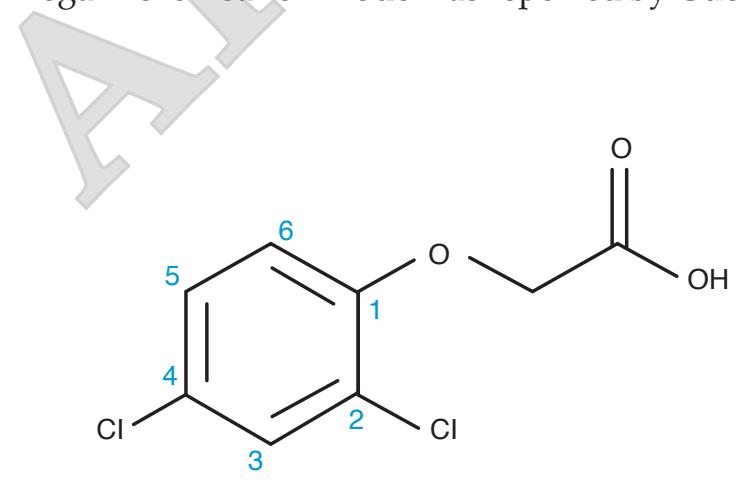

Figure 1. Chemical structure of 2,4-dichlorophenoxyacetic acid (2,4-D).
(2019) and Raina and Etter (2010) for determination of 2,4-D in cereals and surface water. However, the application of liquid-liquid extraction with low temperature precipitation technique for the extraction of 2,4-D prior to quantification has not been explored, and this is the first report of such study. Combination of these techniques has the advantage of small volume of solvent needed for the extraction and it is preferred due to its simplicity and cost effectiveness. Moreover, there is no method established for the determination of 2,4-D in palm oil matrices, although 2,4-D is listed as the major herbicide used in oil palm plantation after glyphosate and metsulphuron methyl (Ainie et al., 2007). As palm oil is being used as one of the key ingredients in many food products, it is important to monitor the presence of contaminants in the $\mathrm{CPO}$, by developing a reliable analytical method for the analysis of 2,4-D in this matrix. Therefore, this article demonstrates a simple and economical analytical method for the determination of 2,4-D in CPO using liquid-liquid extraction and low temperature precipitation technique coupled with LC-QToF-MS application.

\section{MATERIALS AND METHODS}

\section{Chemicals and Reagents}

All chemicals and reagents used in this study were of analytical or liquid chromatography grade. Methanol was obtained from Merck whereas formic acid, which is used as an additive in the mobile phase, was obtained from Fisher Scientific (USA). Deionised water from Milli-Q water purification system (Millipore Corp., USA) was used throughout the method development. 2,4-D (99\% purity) standard material was purchased from Dr. Ehrenstorfer (Ausburg, Germany). All chemicals and standard solutions prepared were stored in a freezer (ProTech CF500) at the temperature of $-20^{\circ} \mathrm{C}$ prior to use.

\section{CPO Samples}

CPO samples were obtained from several local palm oil mills in Malaysia and subjected to drying using anhydrous sodium sulphate prior to usage. These samples were pre-tested for any residual 2,4-D to avoid interference during method development.

\section{Apparatus}

A five digit analytical balance (Sartorius SECURA 2250, Missouri, USA), ultrasonic equipment from Branson 5510 (Danbury, CT, USA), vortex mixer (model 37600 from Barnstead/ 
Thermolyne Inc.), 2-in-1 heater and magnetic stirrer - IKA Laboratory Equipment (C-MAG HS 7), Germany and centrifugation system (Sigma 2-16P Sartorius, Missouri, USA and Thermo Scientific Heraeus Megafuge 8R, Massachusetts, USA) were used throughout the study. Adjustable micro-pipettes, between $10.0 \mu \mathrm{l}$ to $100 \mu \mathrm{l}, 100 \mu \mathrm{l}$ to $1000 \mu \mathrm{l}$ and $1000 \mu \mathrm{l}$ to $5000 \mu \mathrm{l}$ together with the pipette tips were purchased from Eppendorf (Hamburg, Germany). Consumables such as $2.0 \mathrm{ml}$ capacity amber microvials (Agilent Technologies, USA), plastic pasteur pipettes, scintillation vials, self-standing Falcon tubes and test tubes were consumed in the study. Volumetric flasks with the scale of $10.0 \mathrm{ml}, 25.0 \mathrm{ml}, 50.0 \mathrm{ml}$ and $100.0 \mathrm{ml}$ (Grade A) were used for the preparation of stock and working solutions.

\section{2,4-D Standard Solutions}

2,4-D stock solution $\left(100.0 \mu \mathrm{g} \mathrm{ml}^{-1}\right)$ was prepared in acetone by dissolving $10.10 \mathrm{mg}$ of 2,4-D standard material in a $100.0 \mathrm{ml}$ volumetric flask. Then, 2,4$\mathrm{D}$ intermediate stock solution $\left(10.0 \mu \mathrm{g} \mathrm{ml}^{-1}\right.$ and 1.0 $\mu \mathrm{g} \mathrm{ml}{ }^{-1}$ ) were prepared through dilution using acetone solvent.

2,4-D working standard solutions (5.0-100.0 ng $\mathrm{ml}^{-1}$ ) were prepared by dilution of $0.05,0.10,0.20$, $0.35,0.50,0.70,0.85$ and $1.00 \mathrm{ml}$ intermediate stock solution $\left(1.0 \mu \mathrm{g} \mathrm{ml}^{-1}\right)$ with acetone in each $10 \mathrm{ml}$ capacity volumetric flasks. All working standard solutions were kept in the freezer at a temperature of $-20^{\circ} \mathrm{C}$. 2,4-D working standards were freshly prepared on a weekly basis to be used for the analyses.

\section{2,4-D Matrix Matched Calibration Curve}

Six concentration levels of matrix matched working standard $(5.0,10.0,20.0,35.0,70.0$ and $100.0 \mathrm{ng} \mathrm{ml}^{-1}$ blank matrix) were prepared in blank matrix extract and injected into the LC-MS/MS system in order to construct a matrix matched calibration curve of 2,4-D for the assessment on the effect of matrix components. All analytical protocols for calibration curve establishment were conducted in triplicate.

\section{2,4-D Spiking Samples Preparation}

Spiking and extraction procedure was carried out based on modified method by Yeoh et al. (2019). Blank melted oil sample, $50.000 \mathrm{~g}$, was weighed into a beaker and placed in a temperature controlled water bath at $60^{\circ} \mathrm{C}$, with continuous stirring to ensure sample homogeneity. $0.500 \mathrm{ml}$ of 2,4-D standard $\left(1 \mu \mathrm{g} \mathrm{ml}^{-1}\right)$ was added into the oil sample to obtain final spiking concentration of $10.0 \mathrm{ng} \mathrm{g}^{-1}$. The spiked sample was constantly stirred for $30 \mathrm{~min}$ to allow homogeneity. While stirring, sub-sampling of the mixed sample was carried out by weighing $5.000 \mathrm{~g}$ of the oil sample into eight self-standing centrifuge tubes. Several batches of spiked samples were prepared to obtain sufficient samples for method validation. These samples were stored in the freezer $\left(-20^{\circ} \mathrm{C}\right)$ prior to usage. Similar spiking procedures were carried out for spiking levels of $50.0 \mathrm{ng} \mathrm{g}^{-1}$ and $70.0 \mathrm{ng} \mathrm{g}^{-1}$.

\section{Extraction of 2,4-D from Oil Samples}

Melted oil sample, $5.000 \mathrm{~g}$ (to the nearest 0.001 g), was weighed into a self-standing Falcon tube and $5 \mathrm{ml}$ methanol was added into the tube. The sample was shaken for $1 \mathrm{~min}$ and was left in the water bath at $60^{\circ} \mathrm{C}$ for $1 \mathrm{~min}$ before shaking for another $1 \mathrm{~min}$. The same step was repeated until a total of 5 min shaking time was achieved. This intermittent heating step during extraction is important to ensure the oil sample will not solidify and remains homogenised for higher extraction efficiency and better percentage of recovery (Khairuddin et al., 2021). The sample was then centrifuged at 7000 $\mathrm{rpm}(5204 \times \mathrm{g})$ for $15 \mathrm{~min}$ and was followed by low temperature precipitation step in the freezer $\left(-20^{\circ} \mathrm{C}\right)$ for $1 \mathrm{hr}$ for phase separation.

After $1 \mathrm{hr}$, the sample was taken out from the freezer and an aliquot of the methanol layer $(1 \mathrm{ml})$ was transferred into sample vial and shaken with vortex mixer for $3 \mathrm{~s}$ prior to analysis using LCQToF-MS system. Seven replicates were prepared for each concentration levels and injected in random order to minimise instrumental drift. Recovery of 2,4-D in CPO was calculated using Equation (1):

$$
\% \text { Recovery }=\frac{\begin{array}{c}
\text { Amount of 2,4-D } \\
\text { in sample }
\end{array}}{\begin{array}{c}
\text { Amount of 2,4-D } \\
\text { added (theoretical) }
\end{array}} \times 100 \%
$$

\section{Liquid Chromatography Tandem Mass Spectrometer}

LC-QToF-MS analysis was conducted using AB Sciex Triple ToF (Model 5600, USA). The system was equipped with Analyst ${ }^{\circledR}$ Instrument Control version 1.7 software and MultiQuant ${ }^{\circledR}$ version 3.0.2 software. In this study, electrospray ionisation (ESI) type with negative mode was selected. Mass spectrometry (MS) parameters settings were as followed: curtain gas, $25 \mathrm{psi}$; ion source gas (GS1), 40 psi; ion source gas 2 (GS2), 40 psi; source temperature, $450^{\circ} \mathrm{C}$; and ion spray voltage, $4000 \mathrm{~V}$. Kinetex $\mathrm{C}_{18} 100$ A capillary column $(50 \mathrm{~mm} \times 2.1 \mathrm{~mm}$ $\times 1.7 \mu \mathrm{m}$ ), attached to the guard column (Security Guard $^{\mathrm{TM}}$ ULTRA cartridges for UHPLC $\mathrm{C}_{18}$, an internal diameter of $3.0 \mathrm{~mm}$ ) were both provided by Phenomenex ${ }^{\mathrm{TM}}$ (USA). Mobile phase A and B 
were $0.1 \%(v / v)$ formic acid in deionised water and $100 \%$ methanol, respectively at the flow rate of 0.3

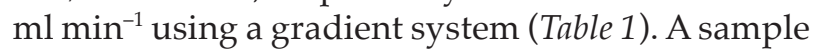
of $10 \mu \mathrm{l}$ was injected into the LC-QToF-MS system with a total analysis time of $15 \mathrm{~min}$ for each sample.

Determination of 2,4-D was performed via pseudo-multiple reaction monitoring (MRM) where the LC-QToF-MS is operated in MRM mode with optimised collision energy (CE) and collision energy spread (CES), in which an MRM transition is defined for each target ion. Table 2 shows the optimised MS parameters for two ion transitions of 2,4-D. The monoisotopic mass of 2,4$\mathrm{D}$ is 219.97 a.m.u. Under negative ionisation mode, formation of negative molecular ion for 2,4-D has been achieved through deprotonation with mass per charge $(\mathrm{m} / \mathrm{z})$ of 218.96 . Therefore, the precursor ion for 2,4-D has been observed at $\mathrm{m} / \mathrm{z} 218.96$. As for the fragment ions (daughter ions), fragment ion with the highest signal was selected as the quantifying ion, while fragment ion with second highest signal was selected as the qualifying ion to ensure method specificity and for the confirmation of the analysis (Andrade et al., 2015). Figure 2 shows the mass spectrum of the 2,4-D fragment ions, with $\mathrm{m} / \mathrm{z} 161$ as the highest ion and m/z125 as the second highest ion.

\section{RESULTS AND DISCUSSION}

\section{Validation of the Developed Method}

Linearity and matrix effect. Two six-point calibration curves for 2,4-D in acetone and matrix matched at different concentrations (5.0, 10.0, 20.0, 35.0, 70.0 and $100.0 \mathrm{ng} \mathrm{ml}^{-1}$ ) were constructed to
TABLE 1. MOBILE PHASE GRADIENT SYSTEM USED IN THE RESIDUAL 2,4-D ANALYSIS USING LC-MS/MS-QTOF

\begin{tabular}{|c|c|c|c|}
\hline $\begin{array}{l}\text { Time } \\
(\min )\end{array}$ & 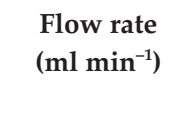 & $\begin{array}{c}\text { Formic acid, } \\
0.1 \% \text { (A) } \\
(\%)\end{array}$ & $\begin{array}{c}\text { Methanol (B) } \\
(\%)\end{array}$ \\
\hline 0.00 & 0.30 & 95 & 5 \\
\hline 5.00 & 0.30 & 5 & 95 \\
\hline 8.00 & 0.30 & 5 & 95 \\
\hline 9.00 & 0.30 & 95 & \\
\hline 15.00 & 0.30 & 95 & 5 \\
\hline TABLE & $\begin{array}{r}\text { OPTIMUM } \\
\text { BY N }\end{array}$ & $\begin{array}{l}\text { ARAMETER FO } \\
\text { ANUAL TUNIN }\end{array}$ & OBTAI \\
\hline $\begin{array}{l}\text { Term } \\
\text { used }\end{array}$ & $\begin{array}{c}\text { Ion } \\
\text { transition } \\
(\mathrm{m} / \mathrm{z})\end{array}$ & $\begin{array}{ll}\text { DP } & \text { CE } \\
\text { (V) } & \text { (V) }\end{array}$ & Remark \\
\hline 2,4-D 1 & $218.9 / 160.9$ & $-20 \quad 10$ & Quantifying ion \\
\hline 2,4-D 2 & $218.9 / 124.9$ & -20 & Qualifying ion \\
\hline
\end{tabular}

Note: DP - declustering potential; CE - collision energy; CES collision energy spread.

confirm the suitability of the chromatographic condition for this study (Figure 3) as well as to investigate the effect of matrix on the method performance. Upon visual evaluation, the calibration curves exhibited linear patterns with $\mathrm{r}^{2}$ of more than 0.99 for both curves.

A big slope difference could be observed when both calibration curves were compared. The linear equations of the curves were used to calculate the matrix effect, which may exist due to the nature of the matrix and its co-eluting matrix components (Norizah et al., 2020; Yeoh et al., 2019). As expected,

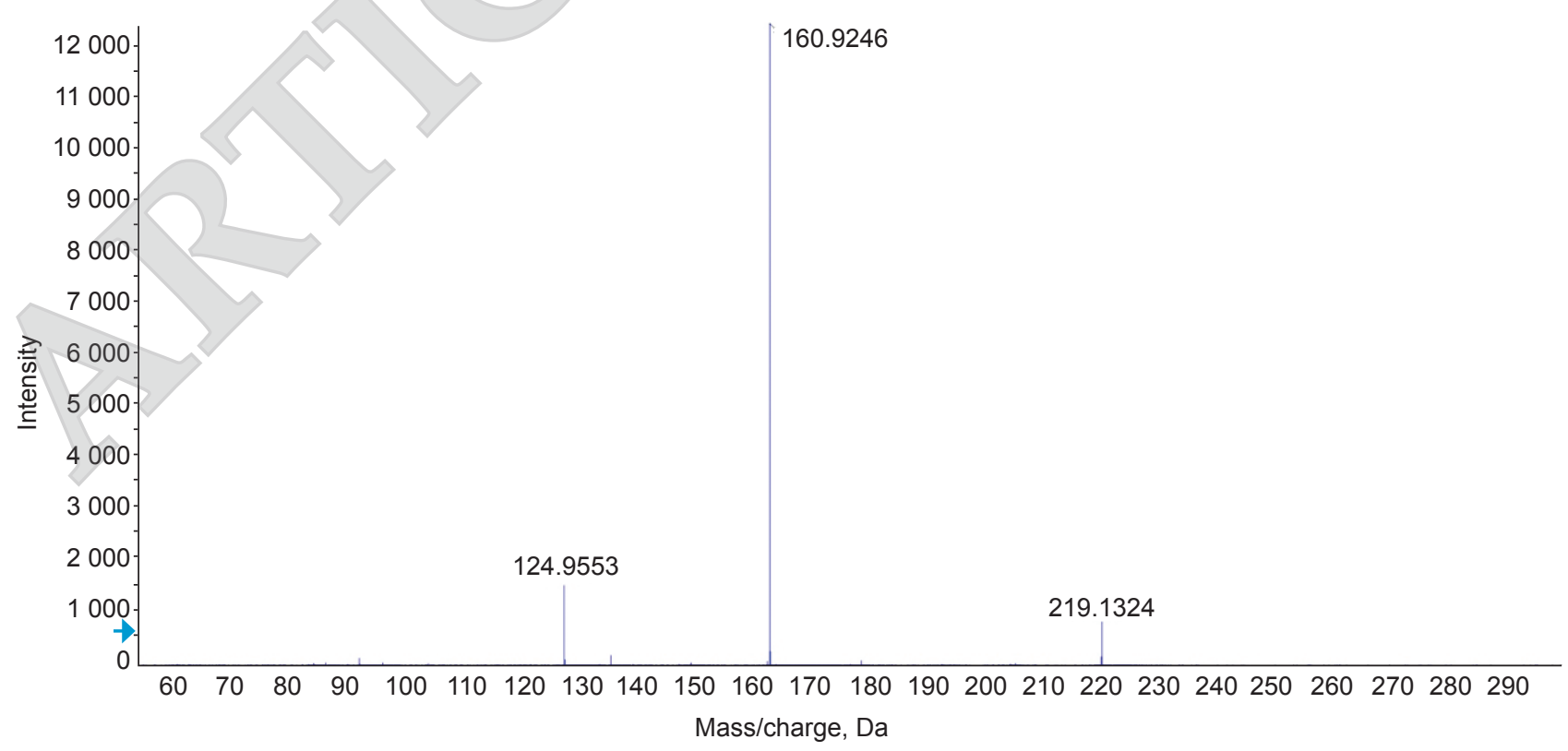

Figure 2. Mass spectrum for 2,4-D fragment ions. 


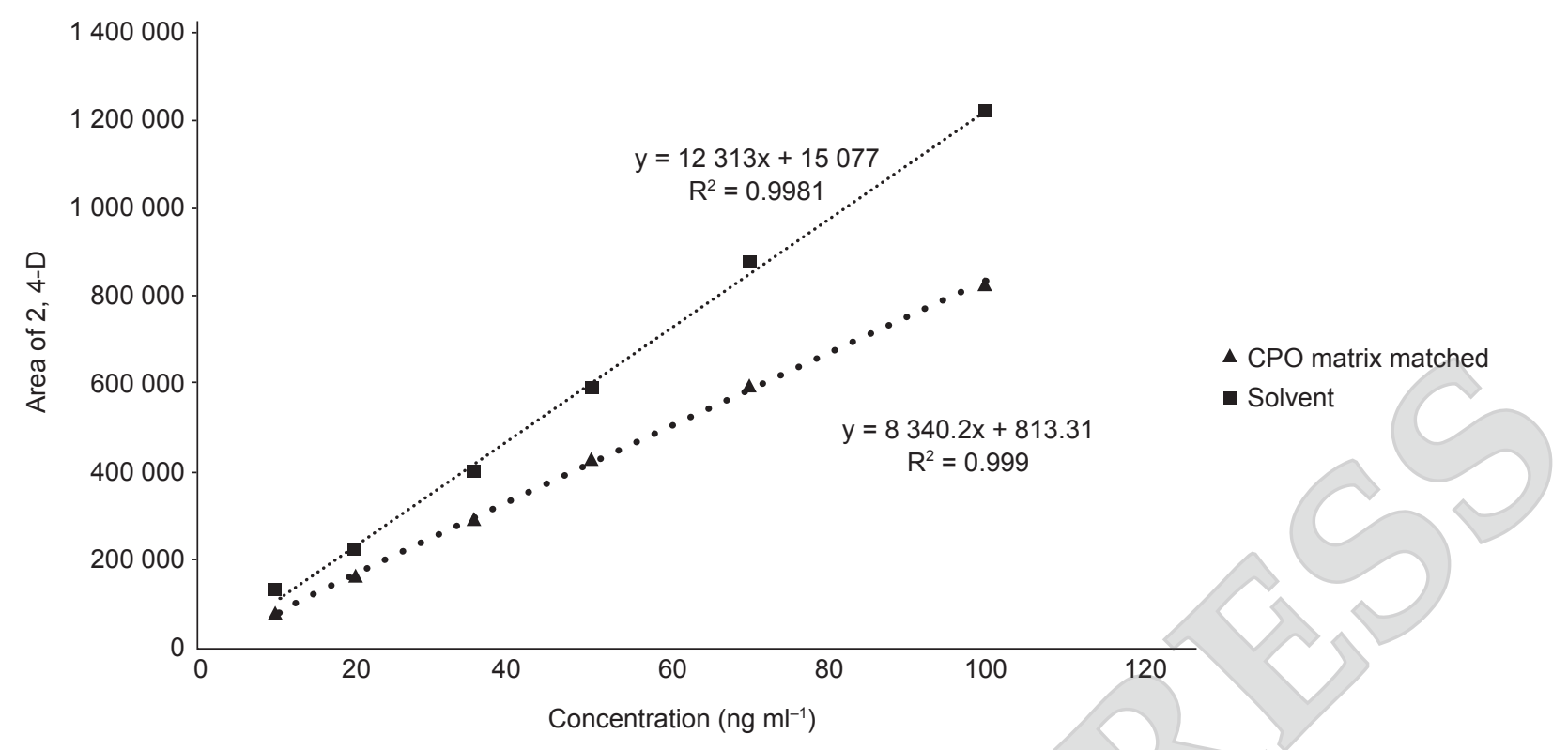

Figure 3. Comparison of calibration curve of 2,4-D plotted based on 2,4-D working standards in acetone and CPO.

the difference of slope showed that there was a significant matrix effect for the analysis of 2,4-D in CPO using LC-QToF-MS and thus, will affect the experiment results. Calculation of matrix effect was determined using Equation (2) as described by Walorczyk (2014) and Yeoh et al. (2019), and was found to be $-46.2 \%$ showing that 2,4-D signal suffered ionisation suppression effect from the matrix.

$$
\begin{aligned}
& \text { Matrix effect }=\left(1-\frac{\text { Solvent slope }}{\text { Matrix matched }}\right) \times 100 \% \\
& \text { slope }
\end{aligned}
$$

Therefore, to eliminate matrix effect, in the process of method validation, matrix matched calibration was used for quantification of 2,4-D in CPO.

Method selectivity. Figure 4 shows the comparison of chromatograms of blank CPO and 2,4-D signal. It could be clearly seen that the signal for 2,4-D was detected at a retention time of $4.45 \mathrm{~min}$ with no other interfering signals, indicating satisfactory selectivity of the developed method. Selectivity of 2,4-D signal in CPO is also aided by the capability of LC-QToFMS to perform multiple reaction monitoring on the specified precursor and fragment ions of 2,4-D.

\section{Limit of detection (LOD) and limit of quantification} $(L O Q)$. In this work, the LOD and LOQ value for 2,4-D in $\mathrm{CPO}$ was determined using the calibration curve of 2,4-D against CPO matrix-matched as reported by Leito (2017). The LOD value was estimated based on the 3.3 times residual standard deviation of $\mathrm{y}$ of the calibration curve and 10 times of the residual standard deviation of $y$ of the calibration curve for LOQ value.
Results from the calculation showed that the LOD and LOQ from analysis of 2,4-D in CPO was $5.1 \mathrm{ng} \mathrm{g}^{-1}$ and $15.5 \mathrm{ng} \mathrm{g}^{-1}$, respectively. However, experimental recovery was able to quantify as low as $10.0 \mathrm{ng} \mathrm{g}^{-1}$, with acceptable recoveries around $90 \%$ to $100 \%$, justifiable with the current advancement of chromatography technology. Therefore, the LOD and LOQ were estimated at $5.0 \mathrm{ng} \mathrm{g}^{-1}$ and $10.0 \mathrm{ng} \mathrm{g}^{-1}$, respectively, which are close to the value obtained from the calculation. LOD and LOQ of the analytical method is capable of detecting 2,4-D residue in $\mathrm{CPO}$ at levels lower than the European Union (EU) and Malaysia maximum residue limit (MRL) value for 2,4-D in palm oil which was set at $0.05 \mathrm{mg} \mathrm{kg}^{-1}$ (European Commission, 2019; Malaysian Federal Government Gazette, 2020).

Precision-Repeatability. Spiked CPO samples at concentration of 10.0, 50.0 and $70.0 \mathrm{ng} \mathrm{g}^{-1}$ were measured in one analytical run under similar operating conditions, measurement procedure, analyst and instrument. Results of the precision study were tabulated in Table 3. Relative standard deviations (RSD) obtained from different concentrations of spiked samples were much lower than acceptable limit of $20 \%$, as prescribed in the guideline by the European Commission (2017), indicating high individual repeatability between measurement data.

Precision-Intermediate precision. Similar measurement procedure with several changes, i.e. analysts, time of analysis, different batches of reagents and column efficiency were employed for spiked samples concentration of $10 \mathrm{ng} \mathrm{g}^{-1}$. From Table 4, method intermediate precision for samples spiked at $10 \mathrm{ng} \mathrm{g}^{-1}$ was found to have satisfactory 


\section{[2,4-D] 160.5000-161.5000}

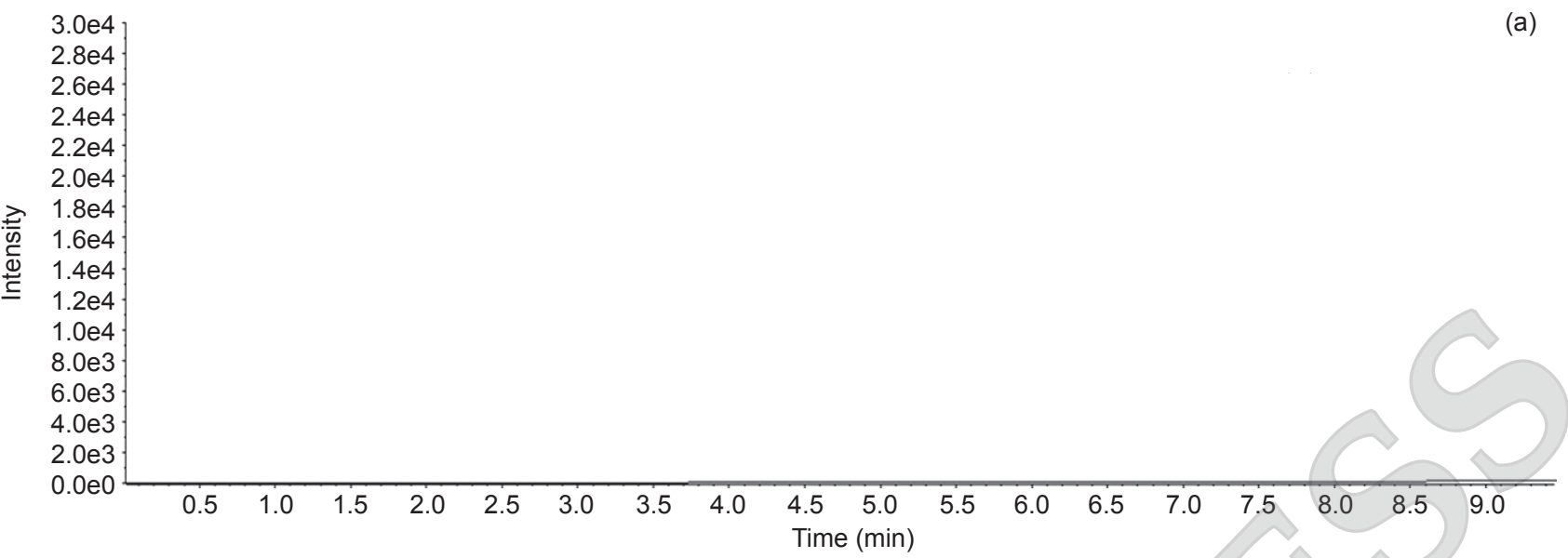

$[2,4-D] 160.5000-161.5000$

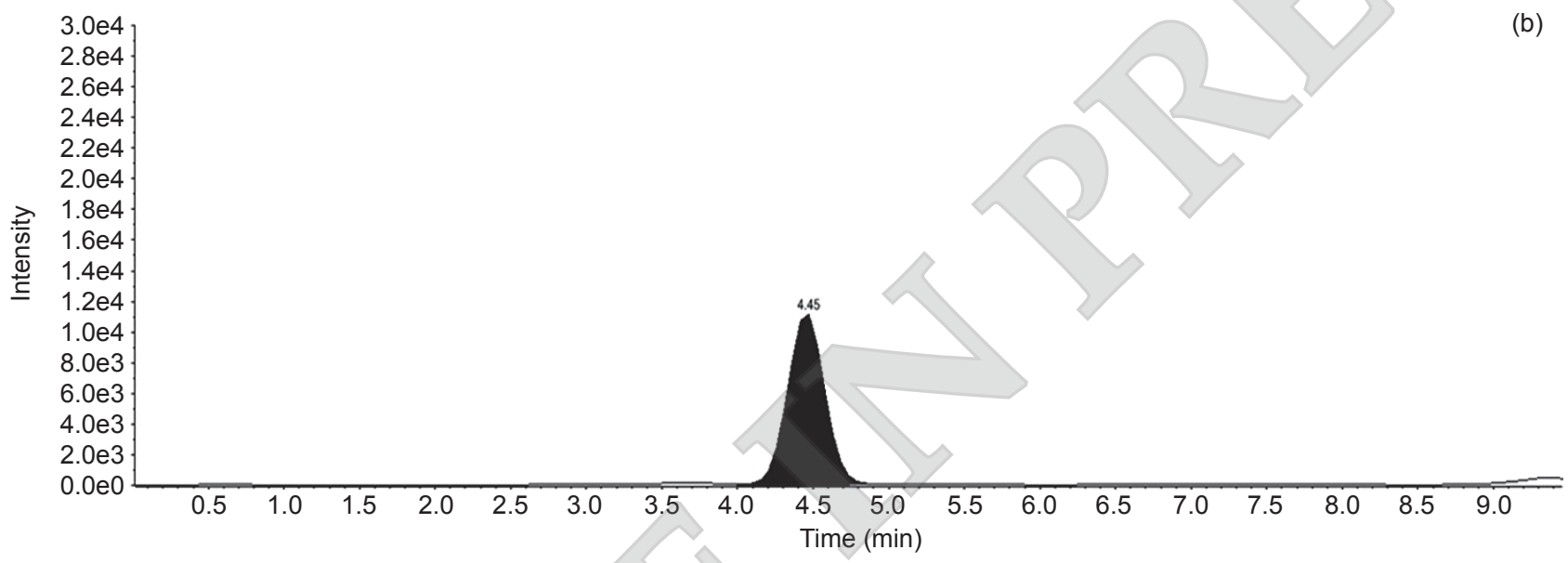

Figure 4. Representative chromatogram of (a) blank CPO sample, and (b) CPO sample spiked with $10 \mathrm{ng} \mathrm{ml}^{-1}$ 2,4-D working standard solution.

TABLE 3. RECOVERY STUDIES FOR ANALYSIS OF 2,4-D IN CPO AT THE CONCENTRATION OF 10, 50 AND $70 \mathrm{ng} \mathrm{g}^{-1}$

\begin{tabular}{ccc}
\hline $\begin{array}{c}\text { Concentration } \\
\left(\mathbf{n g ~ g}^{-1}\right)\end{array}$ & $\begin{array}{c}\text { Average recovery for analysis of } \\
\text { residual } \mathbf{2 , 4 - D} \text { in CPO }(\%) \\
(\mathbf{n = 6})\end{array}$ & $\begin{array}{c}\text { RSD } \\
\mathbf{( \% )}\end{array}$ \\
\hline 10.0 & 117.30 & 5.2 \\
50.0 & 88.07 & 9.9 \\
70.0 & 85.14 & 8.3 \\
\hline
\end{tabular}

TABLE 4. METHOD INTERMEDIATE PRECISION FOR SAMPLES SPIKED AT $10 \mathrm{ng} \mathrm{g}^{-1}$

\begin{tabular}{|ccccc}
\multicolumn{3}{c}{ SAMPLES SPIKED AT $\mathbf{1 0} \mathbf{n g ~ g}^{-1}$} \\
\hline & $\begin{array}{c}\text { Average recoveries (\%) } \\
(\mathbf{n = 6})\end{array}$ & \multicolumn{3}{c}{$\begin{array}{c}\text { RSD } \\
(\%)\end{array}$} \\
\hline & Day I & Day II & Day I & Day II \\
\hline Analyst 1 & 117.97 & 101.05 & 4.2 & 10.4 \\
Analyst 2 & 116.59 & 114.51 & 5.6 & 6.4 \\
\hline
\end{tabular}

recoveries (70\%-120\%) and RSD well within acceptable criteria of 20\% (European Commission, 2017). Statistical evaluation of the data supports the finding as there was no significance difference between the variation of analyst and time of analysis $(p=0.01)$. It can be said that the developed method was reliable and reproducible (within laboratory).

Recovery experiment. Data from precision experiments (Table 3) were used to determine the recoveries of 2,4-D in CPO samples. The average recoveries of 2,4-D in CPO at three different concentrations (low, medium and high) were found to be between $85 \%$ to $117 \%$, which is acceptable following the guideline stated in European Commission (2017).

Method applicability to real CPO samples. 2,4-D residue in $\mathrm{CPO}$ samples were evaluated using the validated method. Residual 2,4-D was not detected in randomly selected CPO samples from palm oil mills in different states in Malaysia (Figure 5).

\section{CONCLUSION}

A simple, economical and reliable analytical method for analysis of 2,4-D in CPO was developed and validated. Experimental results 


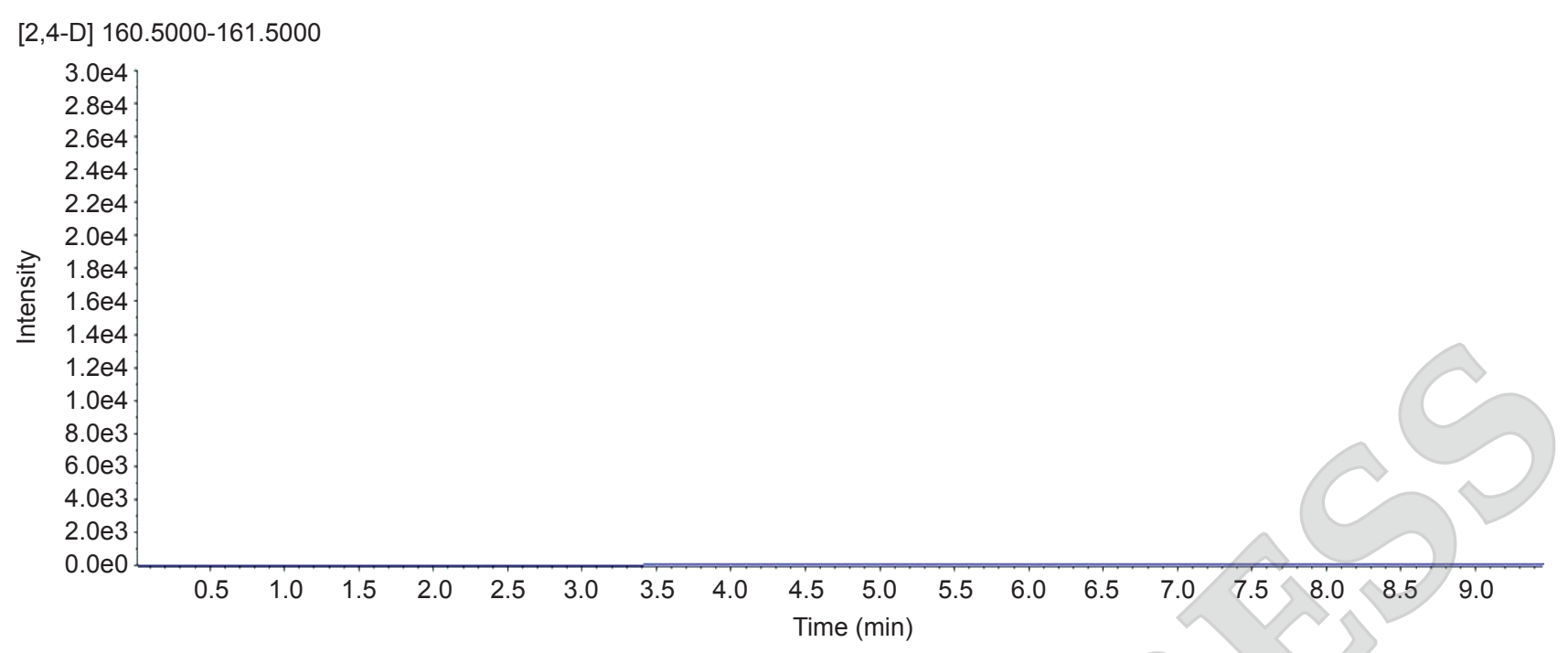

Figure 5. Example of representative chromatogram for residual analysis of 2,4-D in CPO obtained from one of the mills (Mill 1) for CPO monitoring.

revealed good method performance in terms of linearity, matrix effect, selectivity, LOD, LOQ, repeatability, intermediate precision and recovery in $\mathrm{CPO}$ samples. Liquid-liquid extraction with methanol, heating of samples and low temperature precipitation technique combined with LC-MS/MS were efficient in detecting 2,4-D in CPO. The LOD and LOQ of the analytical method is in compliance with the international and national MRL values set hence the method can be used for regulatory monitoring of the presence of 2,4-D residue in palm oil.

\section{ACKNOWLEDGEMENT}

The authors would like to thank the Director-General of MPOB for the permission to publish this article.

\section{REFERENCES}

Ainie, K; Tan, Y A; Norman, K and Yeoh, C B (2007). Pesticide application in the oil palm plantation. Oil Palm Bulletin, 54: 52-67.

Andrade, G C R M; Monteiro, S H; Francisco, J G; Figueiredo, L A; Botelho, R G and Tornisielo, V L (2015). Liquid chromatography-electrospray ionization tandem mass spectrometry and dynamic multiple reaction monitoring method for determining multiple pesticide residues in tomato. Food Chem., 175: 57-65. DOI:10.1016/j. foodchem.2014.11.105.

Chamkasem, N and Morris, C (2016). Direct determination of 2,4-dichlorophenoxyacetic acid in egg and milk by liquid chromatography/tandem mass spectrometry, Laboratory Information Bulletin
LIB \#4605 US Food and Drug Administration. p. $1-9$.

Chen, W; Jiao, B; Su, X; Zhao, Q and Sun, D (2015). Dissipation and residue of 2,4-D in citrus under field condition. Environ. Monit. Assess., 187(5): 302. DOI: $10.1007 / \mathrm{s} 10661-015-4536-0$.

Chen, X; Zhang, H; Wan, Y; Chen, X and Li, Y (2018). Determination of 2,4-dichlorophenoxyacetic acid $(2,4-D)$ in rat serum for pharmacokinetic studies with a simple HPLC method. PLoS ONE, 13(1). DOI: 10.1371 / journal.pone.0191149.

European Commission (2017). Guidance Document on Analytical Quality Control and Method Validation Procedures for Pesticide Residues and Analysis in Food and Feed. Document No. SANTE/11813/2017. 42 pp.

European Commission (2019). EU Pesticides Database. https: / / ec.europa.eu/food/plant/ pesticides / eu-pesticides-database $/ \mathrm{mrls} /$ ? event= search.pr, accessed on 2 April 2021.

Garcia-Reyes, J F; Ferrer, C; Gomez-Ramos, M J; Molina-Diaz, A and Fernandez-Alba, A R (2007). Determination of pesticide residues in olive oil and olives. Trends Anal. Chem., 26(3): 239-251. DOI: 10.1016/j.trac.2007.01.004.

Guo, T; Wang, X; Wang, H; Hu, Y; Zhang, S and Zhao, R (2019). Determination of phenoxy acid herbicides in cereals using high-performance liquid chromatography-tandem mass spectrometry. J. Food Prot., 82(7): 1160-1165. DOI: 10.4315/0362028X.JFP-18-558.

Hua, M Z; Feng, S; Wang, $\mathrm{S}$ and Lu, X (2018). Rapid detection and quantification of 
2,4-dichlorophenoxyacetic acid in milk using molecularly imprinted polymers-surface-enhanced Raman spectroscopy. Food Chem., 258: 254-259. DOI: 10.1016/j.foodchem.2018.03.075.

Ismail, B S; Mehdi, S and Halimah, M (2011). Evaluation of herbicide pollution in the Kerian ricefields of Perak, Malaysia. World App. Sci. J., 15 (1): 5-13.

Jannick, J J and Robert, E P (2008). The Encyclopedia of Fruit and Nuts. CABI. p. 123.

Khairuddin, N S K; Yeoh, C B; Sulaiman, N; Ahmad Bustamam, F K; Halimah, M and Ismail, S (2021). Determination of metsulphuron methyl in crude palm oil using liquid chromatography triple quadrupole mass spectrometer. Malaysian J. Anal. Sci., 25(2): 352-362.

Leito, I (2017). Validation of liquid chromatography mass spectrometry (LC-MS) methods (Analytical Chemistry) course. https://sisu.ut.ee/sites / default / files / lcms_method_validation / files / lcms_pdf_161017.pdf, accessed on 8 October 2020.

MacBean, C (2012). 2,4-D. A World Compendium, The Pesticide Manual, $6^{\text {th }}$ Edition (Colin MacBean ed.). British Crop Production Council, United Kingdom. p. 291-297.

Malaysian Federal Government Gazette (2020). Food Act 1983 - Food (Amendment) (No. 3) Regulations 2020. 38 pp.

Mat Dian, N L H; Ying, W S; Yen, F J; Meganathan, P; Nik Ibrahim, N M A; Mohd Hassim, NA; Wasoh, $\mathrm{H}$ and Ming, L O (2019). Palm-based vitamin E (tocotrienol-rich fraction) has excellent stability in chewable tablet after one-year of storage at ambient temperature. J. Oil Palm Res., 31(4): 662-669. DOI: 10.21894/ jopr.2019.0023.

Mehdi, S; Ismail, B S and Halimah, M (2011). Sorption kinetics of 2,4-dichlorophenoxyacetic acid in selected agricultural soils of Malaysia. Res. J. Environ. Toxic., 5(1): 39-48. DOI: 10.3923/ rjet.2011.39.48.

MPOB (2020). Malaysian Oil Palm Statistics 2020. http://bepi.mpob.gov.my/index.php/en/ export / export-2020 / monthly-export-of-oil-palmproducts-2020.html, accessed on 2 April 2021.

Murphy, T R (2011). Grass Pasture and Hay Field Herbicides. Weed Science. p. 1-3.

Ngah, N; Omar, D; Juraimi, AS and Hailmi, M (2011). Leaf surface characteristics of selected Malaysian weed species of oil palm. J. Agrobiotech., 2: 53-65.

Norizah, H; Ainie, K; Raviraj, S and Kaushik, B (2020). High throughput residue analysis of indaziflam and its metabolites in palm oil using liquid chromatography-tandem mass spectrometry. J. AOAC International, 103(5): 1237-1242. DOI: 10.1093 / jaoacint/ qsaa041.

Pande, G; Akoh, C C and Lai, O M (2012). Food uses of palm oil and its components. Palm Oil: Production, Processing, Characterization and Uses (Lai, O M; Tan, C P and Akoh, C C eds.). AOCS, United States of America. p. 571-582.

Raina, R and Etter, M L (2010). Liquid chromatography with post-column reagent addition of ammonia in methanol coupled to negative ion electrospray ionization tandem mass spectrometry for determination of phenoxyacid herbicides and their degradation products in surface water. Anal. Chem. Insights, 5: 1-14. DOI: $10.4137 /$ aci.s3148.

Walorczyk, S (2014). Validation and use of a QuEChERS-based gas chromatographic-tandem mass spectrometric method for multiresidue pesticide analysis in blackcurrants including studies of matrix effects and estimation of measurement uncertainty. Talanta, 120: 106-113. DOI: 10.1016/j. talanta.2013.11.087.

Yeoh, C B; Farah Khuwailah, A B; Najwa, S; Nik Sasha Khatrina, K; Tay, M G and Saw, M H (2019). Development of analytical method for determination of thiosultap-disodium residue in palm oil matrix. J. Oil Palm Res., 31(4): 634-640. DOI: 10.21894/jopr.2019.0028.

Yeong, S H; Idris, Z and Abu Hasan, H (2012). Palm oleochemicals in non-food applications. Palm Oil: Production, Processing, Characterization and Uses (Lai, O M; Tan, C P and Akoh, C C eds.). AOCS, United States of America. p. 596-620. 